\title{
Hybrid converter for electric vehicle battery charging with power quality features
}

\section{B.R. Ananthapadmanabha, Rakesh Maurya and Sabha Raj Arya*}

Department of Electrical Engineering,

Sardar Vallabhbhai National Institute of Technology,

Surat, 395007, India

Email: ananthpbr@gmail.com

Email: rmaurya@eed.svnit.ac.in

Email: sabharaj79@gmail.com

*Corresponding author

\begin{abstract}
The power factor correction converters for electric vehicle battery chargers result in higher conduction losses and reverse recovery losses when fed from low voltage supply line. To overcome the above problem, a hybrid switched capacitor Cuk converter based power factor correction converter is proposed which has high stepup gain and low-voltage stress across the switch. The converter offers a very significant efficiency improvement at low voltage supply line over the single-switch buck-boost converters (including fly-back, SEPIC and Cuk topologies) and conventional two-switch buck-boost cascaded converters. In this paper, the design and simulation of the proposed converter is carried out in continuous current mode (CCM). The modelling and simulation are done in Matlab-Simulink environment. The power quality indices like THDs $\left(\mathrm{v}_{\mathrm{THD}}, \mathrm{i}_{\mathrm{THD}}\right), \mathrm{PF}$ are evaluated to demonstrate the performance of the converter. The converter is evaluated both in steady state and transient conditions.
\end{abstract}

Keywords: battery charging; Cuk converter; harmonics; electric vehicle; power factor.

Reference to this paper should be made as follows: Ananthapadmanabha, B.R., Maurya, R. and Arya, S.R. (2019) 'Hybrid converter for electric vehicle battery charging with power quality features', Int. J. Computational Systems Engineering, Vol. 5, No. 1, pp.24-35.

Biographical notes: B.R. Ananthapadmanabha received his MTech in Electrical Engineering with a specialization in power electronics from the B.M.S. College of Engineering, Bangalore, India, in 2005 and he is currently pursuing his $\mathrm{PhD}$ in Electrical Engineering at the Sardar Vallabhbhai National Institute of Technology, Surat, Gujarat, India. In 2005, he joined Hynetic electronics, Bangalore as a Field Application Engineer working in the area of dc/dc converters, battery chargers. In 2011 he joined in the Incap CMS ltd, Bangalore as a Project Manager for the product management of UPS, inverters. His fields of interest include power electronics, power quality and design of $\mathrm{dc} / \mathrm{dc}$ converters.

Rakesh Maurya received his MTech in Power Electronics and Electric Drives and $\mathrm{PhD}$ in Electrical Engineering from the Indian Institute of Technology Roorkee, India in 2002 and 2014 respectively. He is currently serving as a faculty member in the Department of Electrical Engineering, Sardar Vallabhbhai National Institute of Technology Surat, Gujarat, India. His fields of interest include design of switching power converters, high power factor AC/DC converters, hybrid output converter, advanced electric drives and applications of real-time simulator for the control of power converters.

Sabha Raj Arya received his Master of Technology in Power Electronics and ASIC Design from the Motilal National Institute of Technology, Allahabad, in 2004 and PhD from the Indian Institute of Technology (I.I.T) Delhi, New Delhi, India, in 2014. He is joined as an Assistant Professor in the Department of Electrical Engineering, Sardar Vallabhbhai National Institute of Technology, Surat. His fields of interest include power quality, power factor correction converter and distributed power generation. He received Two National Awards namely INAE Young Engineer Award from the Indian National Academy of Engineering, POSOCO Power System Award from Power Grid Corporation of India in the year of 2014 for his research work. 


\section{Introduction}

Various applications like switched-mode power supplies (SMPS), uninterruptable power supplies and adjustable speed drives require AC-DC power conversion at its input (Mohan et al., 2007). In the present situation, high value of harmonics in supply system has become an important issue because of exorbitant deployment of power electronics (Rashid, 2011).The proliferation of utility-connected power electronic converters has given momentum to the research in harmonic elimination and power factor improvement. The different applications that use power electronics are power supplies for personal computers, mobile phone chargers, home appliances and battery chargers for electric vehicles (EVs), etc. The tremendous increase in growth of EVs can create serious problems of power quality in existing grids (Mikkili and Panda, 2016; Liu et al., 2011). The power-factor-correction converters are of prime importance in the application of charging EV battery. As the number of EV battery chargers in residential installation increase, the harmonic level in power distribution system increases, and yields in reduction in the life of the distribution transformer (Rutherford and Yousefzadeh, 2011). The SMPS are mainly used in these applications. In three-phase four-wire balanced system, the current in the neutral is expected to be small (Zadeh and Farjah, 2009). Neutral currents come into picture even under the situations of single phase balanced loads (Inoue et al., 2003). These power supplies are connected to utility through un-controlled full wave rectifier and a capacitor. This type of AC-DC converter inherently draws non-sinusoidal current (Baggini, 2008). The harmonic emission of such converter, will be high thus amounting to a high THD and poor power factor violating the regulatory limits (Putrus et al., 2009). It is a known fact that THD of input current drawn by a rectifier having a capacitor at its output for filtering purposes, is around $75 \%$ to $85 \%$ or more than this value depend upon value of connected capacitor. This fact in turn results in low power factor and high crest factor. It is required to develop converters which meets the power quality indices at its ac input as imposed by IEEE/IEC standards (International Standard, 2000; IEEE Standard $519,1992)$. These standards recommend a power factor above 0.9 and THD below 5\% for these ac-dc converters. These standards address as class-D applications which includes power consumption $<600 \mathrm{~W}$, i.e., $<16 \mathrm{~A}$, under single phase input. There are many AC-DC converter topologies reported in the literature to meet the recommended PQ standards (Singh et al., 2003; Singh et al., 2011). Two-stage PFC converters are widely used in practice in which first stage is for the power factor correction and second stage is for voltage regulation. Different requirements call for different types of converters in the second stage.

The dual purpose of output voltage regulation along with input current shaping can be achieved with both modes [continuous current mode (CCM) and DCM] of converter operation (Singh et al., 2003, 2011). In DCM, the possibility of inherent PFC exists with the associated disadvantages of high current stress. One can utilise the advantage of low current stress while designing converter for CCM with the associated disadvantages of increased number of sensors. Conventionally, one needs three sensors to sense output voltage, input voltage and inductor current. Because of the above reason, CCM is usually employed for medium and high power applications. The DCM is preferred in low power applications because of high current stress.

However, the efficiency at low line operation is much less compared to its efficiency at high line for boost converters. There is a need to take care of the conduction loss in the switch and reverse recovery loss in the diode, which is predominant at low input voltage. A bigger heat sink is required to dissipate these losses which increase weight and volume of the converter. The basic requirement for reducing the losses at low input voltage is the use of high step-up gain converters. In addition, the converters should also have low switch voltage stress (Kwon and Kwon, 2009). The converters like buck-boost, fly-back, SEPIC and Cuk converters are prospective candidates for the aforesaid purpose, but comparatively, these converters have greatly increased component stresses (Ismail et al., 2008).

Based on literature review, voltage multipliers, transformer based topologies, cascaded converters, coupled inductor based converters and quadratic converters are few converters which have high voltage gain and low switch voltage stress. The cascaded converters and quadratic converters have desired voltage conversion ratio. However, the overall efficiency of the converter is the product of efficiencies of the individual converters. The energy stored in leakage inductance result in high voltage spike during turn-off, which has to be clamped properly to safeguard the switch in case of coupled inductor and transformer based topologies (Kwon and Kwon, 2009). This voltage when clamped results in significant loss. In order to overcome this problem many passive and active clamps have been introduced which bring the additional control complexity (Wai and Duan, 2005).

A converter was proposed in Axelrod et al. (2003) to meet the demand for a higher step-up gain. A switched capacitor circuit integrated with boost converter has been discussed. A conventional step-down and a step-up/ step-down, converter is integrated with a switched capacitor circuit to meet the demand for high step-down gain (Axelrod et al., 2009). In Axelrod et al. (2005), to reap the benefit of high step-up gain, step-up/down converter like Cuk, SEPIC, and Zeta converter are converted to step-up only converter. Thus in comparison with other step-up converters, the duty-cycle that is required by these converters is less in addition to the benefit of less voltage stress across the switch (Axelrod et al., 2003, 2009, 2005). Lower voltage rated MOSFET with lower on-state resistance can be used as the voltage stress is low. In addition, Schottky diodes can be used which will lessen the reverse recovery loss. This leads to improved circuit efficiency as both conduction loss and switching loss are reduced. 
Figure 1 Power factor correction converter using hybrid switched capacitor Cuk converter (see online version for colours)
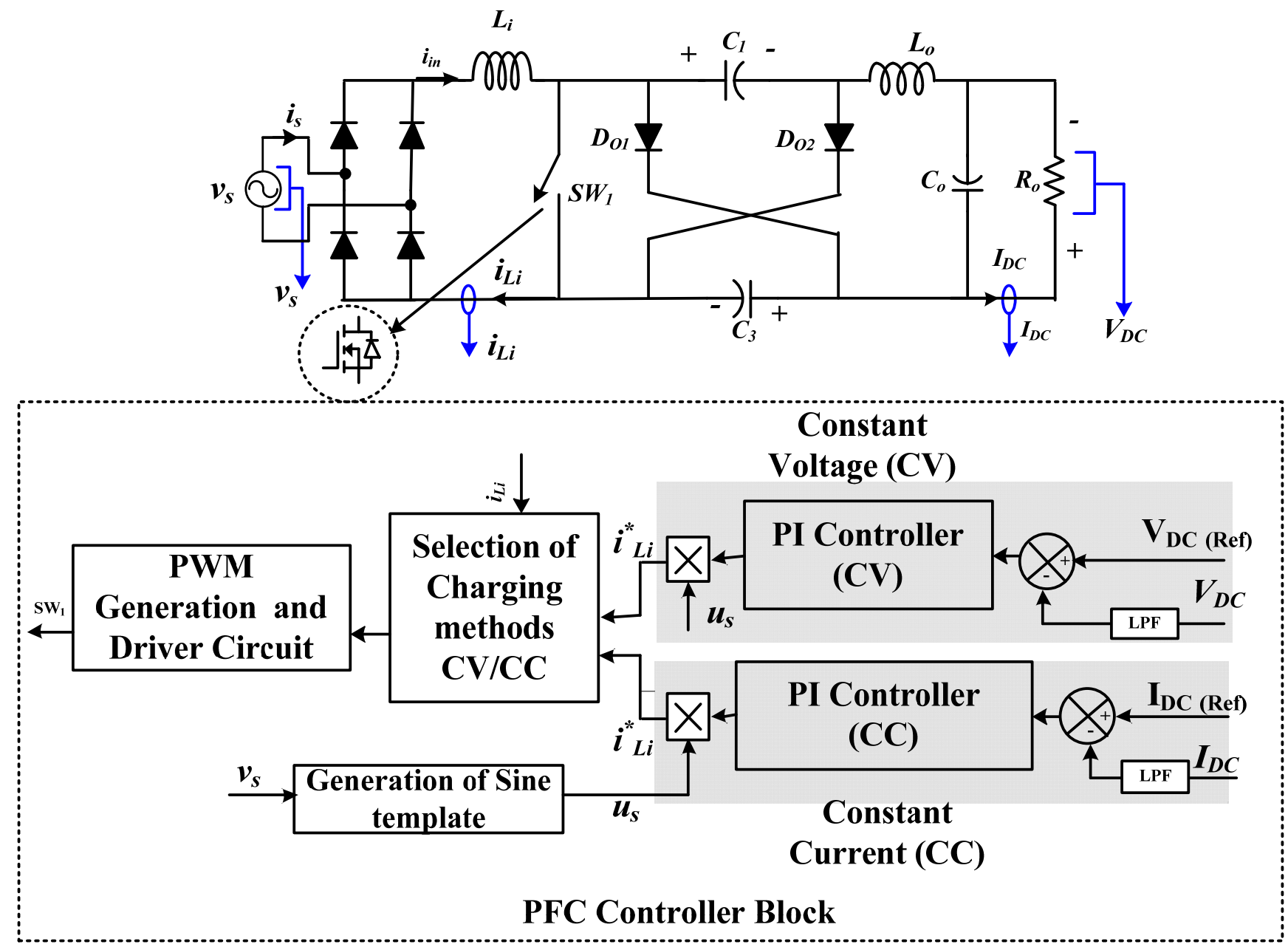

In this paper, an improved power quality converter for universal input $(90 \mathrm{~V}-265 \mathrm{~V})$ which is based on a hybrid switched capacitor Cuk converter is proposed for the application of EV battery charging. The high voltage gain and low switch voltage stress of this proposed converter, results in reduced conduction and switching losses. The average current through the switch is reduced because of the high gain and this results in reduced conduction loss. The reduced switch voltage stress contributes for lowering the switching loss. The reduced voltage across the switch also results in reduction in reverse recovery losses in the output diode, thus contributing for the overall efficiency improvement. As the topology has inductor at AC, side the pulsed current problem which is present in conventional buck boost topologies are absent.

The nominal voltage of the battery pack for the EV application is around $380 \mathrm{~V}$ DC nominal. In Section 2, the hybrid switched capacitor Cuk converter in CCM operation is proposed for charging the battery. In Section 3, the operation of the converter with different modes and waveforms is described. In Section 4, the design criteria of the converter and in Section 5, the basic control that is adopted in simulation is described. The simulation and performance of the converter is discussed in Section 6 with conclusion in Section 7.

\section{System configuration}

Figure 1 shows proposed hybrid switched capacitor Cuk converter. The hybrid switched capacitor Cuk converter which has an uncontrolled rectifier at its input is designed as battery charger. A $230 \mathrm{~V}$ nominal voltage single phase source powers the rectifier. Continuous conduction mode of operation is selected for this converter, with current multiplier approach for power factor correction. The CCM of operation ensures that the current flowing through energy storing elements such as $L_{i}, L_{O}$ is continuous. The proposed converter is designed and simulation is done with resistive and inductive load. 
Figure 2 Operating modes over one switching cycle, (a) Mode I (b) Mode II (see online version for colours)

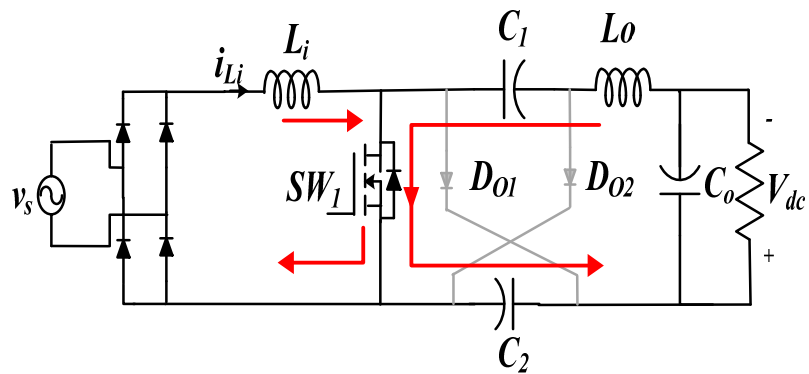

(a)

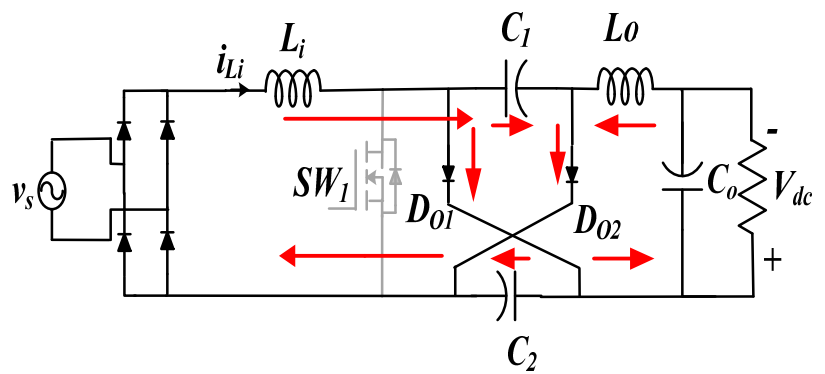

(b)

\section{Operation of hybrid switched capacitor Cuk converter}

Figure 1 shows the proposed circuit. An addition of a capacitor and a diode to the conventional Cuk converter results in switched capacitor variation of Cuk converter. The inter-connections of intermediate capacitors $C_{1}$ and $C_{3}$ change from series to parallel during every period of the switching cycle. The hybrid switched capacitor Cuk converter is designed to operate in CCM, i.e., the current through inductors $i_{L i}, i_{L O}$ and voltages $V_{C 1}$ and $V_{C 3}$ are continuous in a switching period. Figure 2(a) and Figure 2(b) show different modes of operation in a complete switching period and Figure 3 shows the associated waveforms.

- $\quad$ Mode I $[0<t<D t]$ : as shown in Figure 2(a), during this mode, the switch SW1 is turned on. Both the inductors start accumulating energy. Parallelly, the other two intermediate inductors starts shedding its energy in series.

- $\quad$ Mode II $[D t<t<T]$ : as shown in Figure 2(b), the switch is turned off at the beginning of this interval. Both inductors release its energy and the other two capacitors start accumulating energy in parallel as shown.

\section{Design ofhybrid switched capacitor Cuk converter}

Continuous conduction mode is chosen for the design of hybrid switched capacitor Cuk converter. The design is going to ensure output voltage control in addition to power factor improvement and harmonics reduction. The design and selection criterion of these four parameters are in the following section. The input voltage $V_{S}$ applied to the diode bridge rectifier is given as,

$$
v_{s}(t)=V_{m} \sin \left(2 \pi f_{L}\right) t=230 \sqrt{2} \sin (314 t) V
$$

Figure 3 Voltage and current waveforms during one switching period

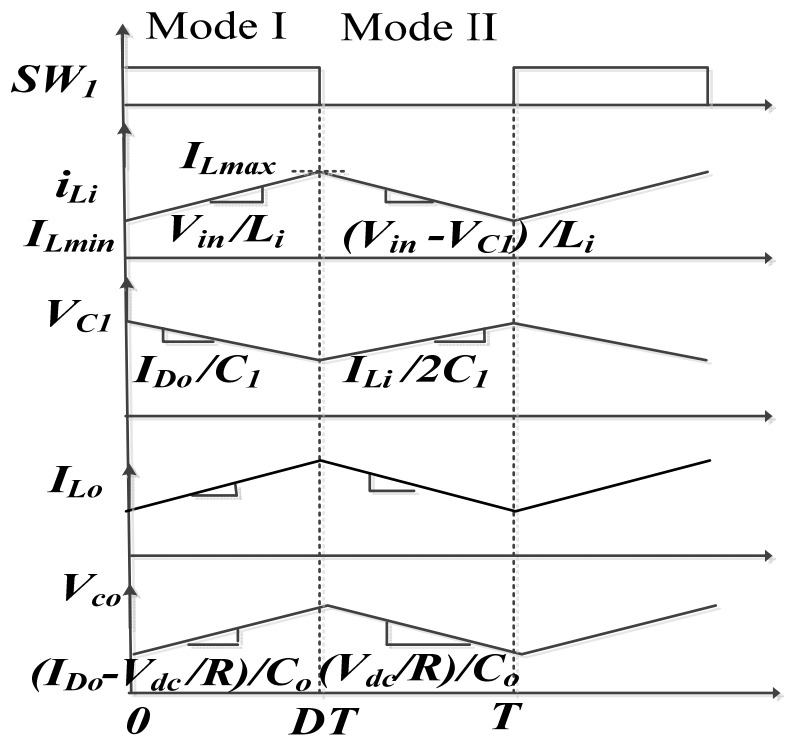

Bridge rectifier has the output voltage equal

$$
V_{\text {in }}(t)=\left|V_{m} \sin \left(2 \pi f_{L}\right) t\right|=|230 \sqrt{2} \sin (314 t)| V
$$

The output voltage of hybrid switched capacitor converter is given as,

$$
V_{d c}=\frac{1+D}{1-D} v_{i n}(t)
$$

The input voltage to the converter dictates the duty-cycle.

$$
D=\frac{V_{d c}-v_{i n}}{V_{d c}+v_{i n}}
$$

\subsection{Design of input inductor}

The value of input inductor is calculated based on the ripple current value of $25 \%$ of the average current.

$$
\begin{aligned}
L_{i c c m} & =\frac{1}{\lambda \cdot} \frac{V_{i n}^{2}(D)}{P_{i}\left(f_{s}\right)} ; \\
L_{i c c m} & =\frac{1}{\lambda \cdot f_{s}} \frac{V_{i n}^{2}(D)}{P_{i}}\left(\frac{V_{d c}-V_{i n m}}{V_{d c}+V_{i n m}}\right),
\end{aligned}
$$


where

$V_{i n m}$ is the peak value of input voltage after the bridge.

$V_{\text {in }} \quad$ is the RMS Value of input voltage after the bridge.

$f_{s} \quad$ is the switching frequency of switch.

$P_{i} \quad$ is the input power.

$\lambda \quad$ is the permitted percentage of ripple current.

The peak to peak ripple current of the inductor $L_{i}$ is taken as $25 \%$ of the RMS current flowing through it. Since the maximum current flows at full load and minimum AC input voltage condition, the operating point is taken as $500 \mathrm{~W}$ with $85 \mathrm{~V}$ as RMS input voltage.

With the duty-cycle value calculated at the peak of minimum input voltage

$$
\begin{aligned}
& \text { i.e. } V_{i n m}=\sqrt{2} v_{s \min }=\sqrt{2} * 85 \mathrm{~V}, \\
& L_{i c \mathrm{~cm}}=\frac{1}{(0.25) .5500} \frac{85^{2}}{500}\left(\frac{400-85 \cdot \sqrt{2}}{400+85 \cdot \sqrt{2}}\right)=5.65 \mathrm{mH} .
\end{aligned}
$$

\subsection{Design of output inductor}

The expression for the inductor placed at the output is given by,

$$
L_{o c c m}=\frac{1}{\lambda} \frac{V_{i n m} \cdot V_{d c}(D)}{P_{i}\left(f_{s}\right)}
$$

$\lambda$ is the permitted percentage of ripple current.

$$
\begin{aligned}
L_{o c c m} & =\frac{1}{\lambda . f_{s}} \frac{V_{i n m} . V_{d c}}{P_{i}}\left(\frac{V_{d c}-V_{i n m}}{V_{d c}+V_{i n m}}\right), \\
L_{\text {occm }} & =\frac{1}{0.25 .5500} \frac{\sqrt{2} .85 .(400)}{500}\left(\frac{400-\sqrt{2} .85}{400+\sqrt{2} .85}\right) \\
& =37.6 \mathrm{mH}
\end{aligned}
$$

Hence, $L_{\text {occm }}$ of $38 \mathrm{mH}$ is chosen for this inductor with peak to peak ripple of $25 \%$ of RMS current.

\subsection{Design of intermediate capacitor}

The peak to peak ripple voltage of the capacitor represented as $k$ is taken as $10 \%$ of the maximum voltage appearing across it. Since the maximum voltage occurs at maximum input voltage with rated load, the operating point is taken as $500 \mathrm{~W}$ with $265 \mathrm{~V}$ RMS as input. Thus the value is calculated as,

$$
\begin{aligned}
C_{1 c c m} & =\frac{2 \cdot P_{i} \cdot(D)}{k \cdot\left(\Delta V_{c}\right) \cdot f_{s} \cdot V_{d c}}, \\
C_{1 c c m} & =\frac{2 \cdot P_{i} \cdot\left(V_{d c}-\sqrt{2} V_{i n m}\right)}{k \cdot\left(V_{d c}+\sqrt{2} V_{i n m}\right)^{2} \cdot f_{s} \cdot V_{d c}},
\end{aligned}
$$

$$
C_{\mathrm{lccm}}=\frac{2 \cdot(500) \cdot(400-\sqrt{2} \cdot 265)}{0.1(400+\sqrt{2} \cdot 265)^{2} \cdot 5500 \cdot 400}=0.2 u F
$$

Hence, the capacitance of $0.5 \mu \mathrm{F}$ is selected for intermediate capacitors $C_{1}$ and $C_{3}$ for continuous conduction. It is noted that maximum input voltage of $265 \mathrm{~V}$ is taken for the calculation.

\subsection{Design of output capacitor}

The peak to peak ripple voltage of the output capacitor $\left(\mathrm{C}_{\mathrm{o}}\right)$ is taken as $4 \%$ of the voltage. Since the output capacitor carries a current at twice the line frequency, the numerical value is calculated as given in (Singh et al., 2011).

$$
C_{o}=\frac{I_{c o}}{2 \cdot \omega \cdot \alpha \cdot V_{d c}},
$$

where

$I_{c o}$ is the current discharged by the capacitor.

$f_{L} \quad$ is the supply frequency.

$\alpha$ is percentage ripple which is suitably assumed as $4 \%$.

$$
\begin{aligned}
C_{o} & =\frac{P_{i}}{2 \cdot \omega \cdot \delta \cdot V_{d c}^{2}}, \\
C_{o} & =\frac{500}{2.314 \cdot 0 \cdot 04 \cdot 400^{2}}=124 u F .
\end{aligned}
$$

Hence, the DC-link capacitor is selected for the application accordingly.

\section{Control of hybrid switched capacitor Cuk converter}

Voltage mode control and current mode control are options available for the hybrid switched capacitor Cuk converter working in DCM and CCM respectively. Summary of control plan is given in this section. The expression for the error between the reference output voltage and the actual voltage is given by

$$
v_{\text {error }}(n)=V_{d c}^{*}(n)-V_{d c}(n)
$$

The error voltage $\left(v_{\text {error }}\right)$ calculated from equation (16) represents deviation in the sensed output voltage and reference output voltage. This error voltage is fed to voltage controller (PI controller) to generate voltage reference. The voltage reference after multiplication with sine template results in reference current signal. This current reference is compare with inductor current and fed to PWM pulse generation block.

The charging cycle of a Li-ion battery (or a similar battery) consists of a constant-current phase and a constant-voltage phase. To reflect this behaviour, this design contains two feedback paths. The first feedback path regulates the voltage in the constant-voltage phase. The voltage obtained is compared with the reference to regulate 
the loop. The second feedback path regulates the current in the constant-current phase once the output current reaches the output-current limit.

\subsection{Small signal model of the hybrid switched capacitor Cuk converter}

From Mode I and Mode II operation of the converter, two sets of differential equations describing each mode of the converter lead to the development of the state space model of the system. Further state space averaging of the two state space model results in an averaged model.

$$
\begin{aligned}
& \frac{d x}{d t}=A x(t)+B u(t): y(t)=C x(t)+E u(t), \\
& A=A_{1} d+A_{2}(1-d), \\
& B=B_{1} d+B_{2}(1-d), \\
& C=C_{1} d+C_{2}(1-d), \\
& E=E_{1} d+E_{2}(1-d) .
\end{aligned}
$$

which is a nonlinear continuous time equation.

To obtain a small signal model around the quiescent operating point, the following small signal perturbation is added to the above averaged model.

$$
\begin{aligned}
x(t) & =X+\tilde{x}(t): y(t)=Y+\tilde{y}(t): u(t)=U+\tilde{u}(t): d(t) \\
& =D+\tilde{d}(t),
\end{aligned}
$$

where

$$
\mathrm{X}>>\tilde{x}(t): \mathrm{Y}>>\tilde{y}(t): \mathrm{U}>>\tilde{u}(t): \mathrm{D}>>\tilde{d}(t)
$$

adding the above perturbations in the averaged model, we get following small signal model,

$$
\begin{gathered}
\frac{d \tilde{x}(t)}{d t}=A \tilde{x}(t)+B \tilde{u}(t)+B_{d} \tilde{d}(t), \\
y(t)=C \tilde{x}(t)+E \tilde{u}(t)+E_{d} \tilde{d}(t),
\end{gathered}
$$

where

$$
\begin{aligned}
& B_{d}=\left(A_{1}-A_{2}\right) X+\left(B_{1}-B_{2}\right) U, \\
& E_{d}=\left(C_{1}-C_{2}\right) X+\left(E_{1}-E_{2}\right) U .
\end{aligned}
$$

taking Laplace transform and simplifying

$$
\begin{aligned}
& \tilde{X}(s)=(s I-A)^{-1}\left[B \tilde{u}(s)+B_{d} \tilde{d}(s)\right] \\
& \tilde{Y}(s)=C(s I-A)^{-1}\left[B \tilde{u}(s)+B_{d} \tilde{d}(s)\right]+E \tilde{u}(s)+E_{d} \tilde{d}(s) .
\end{aligned}
$$

Using the above equation for output, the control-to-output and input-to-output transfer function is given by

$$
\begin{aligned}
& \frac{\tilde{v}_{o}(s)}{\tilde{d}(s)}==C(s I-A)^{-1} B_{d}+E_{d}, \\
& \frac{\tilde{v}_{o}(s)}{\tilde{v}_{i n}(s)}=C(s I-A)^{-1} B+E: \frac{-b \pm \sqrt{b^{2}-3 a c}}{2 a} .
\end{aligned}
$$

In this paper, Leverrier algorithm is used to develop the resolvent matrix $(s I-A)^{-1}$.
Thus the control-to-output transfer function is given by

$$
\begin{aligned}
& \frac{v_{o}(s)}{d(s)}= \\
& \frac{-2 V_{i n}\left[L_{i} C_{1} R D^{\prime} s^{2}+4 L_{i} D^{2} s+R D^{\prime 2}\right]}{2 C_{1} C_{0} L_{i} L_{o} s^{4}+2 L_{i} L_{o} C_{1} s^{3}+\left(D^{\prime 2} C_{0} L_{i} R+D^{\prime 2} C_{0} L_{o} R\right)} . \\
& \left.-2 D^{2} C_{0} L_{i} R+2 L_{i} C_{1} R\right) s^{2} \\
& +\left(D^{\prime 2} L_{i}+D^{\prime 2} L_{o}-4 D^{2} L_{i}\right) s+D^{\prime 2} R \\
& \frac{v_{o}(s)}{d(s)}=\frac{-2 V_{i n}\left[L_{i} C_{1} R D^{\prime} s^{2}+4 L_{i} D^{2} s+R D^{\prime 2}\right]}{2 C_{1} C_{0} L_{i} L_{o} s^{4}+2 L_{i} L_{o} C_{1} s^{3}} \text {. } \\
& +\left(D^{\prime 2} C_{0} L_{i} R+D^{\prime 2} C_{0} L_{o} R\right. \\
& \left.-2 D^{2} C_{0} L_{i} R+2 L_{i} C_{1} R\right) s^{2} \\
& +\left(D^{\prime 2} L_{i}+D^{\prime 2} L_{o}-4 D^{2} L_{i}\right)_{s}+D^{\prime 2} R
\end{aligned}
$$

The open loop transfer function of the converter with the parameter values

$$
\begin{aligned}
& V_{\text {in }}=230 \mathrm{~V}, L_{i}=5.5 \mathrm{mH}, L_{o}=18 \mathrm{mH}, C_{1}=0.5 \mathrm{uF}, \\
& C_{0}=150 \mathrm{uF}, R=160 \mathrm{ohm} D=0.3 \text { and } D^{\prime}=0.7
\end{aligned}
$$

substituted is given by following equation

$$
\begin{aligned}
& \frac{0.0001417 s^{2}+0.9108 s+3.606 e 04}{1.164 e-12 s^{4}+4.851 e-11 s^{3}} \\
& +0.0001242 s^{2}+0.004672 s+38.42
\end{aligned}
$$

From the basic control theory, the controller has been designed as,

$$
G_{c}(s)=\frac{0.000473}{s},
$$

i.e., a controller with integrator gain of 0.000473 and a proportional gain of 1 is designed.

Figure 4 Bode diagram of compensated and uncompensated system (see online version for colours)

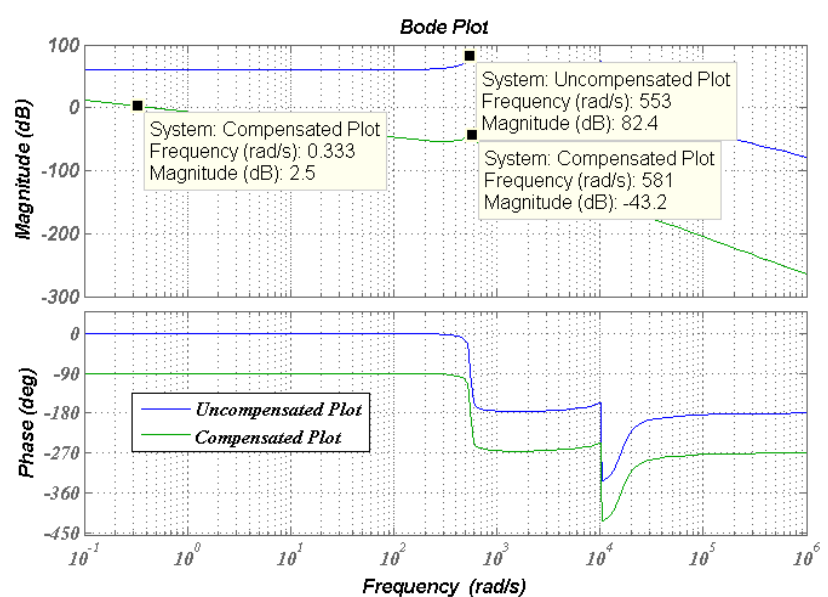

The bode plot of the uncompensated and compensated system is shown in Figure 4. 


\section{Simulation study of hybrid converter}

The Simulink model of Hybrid switched capacitor Cuk converter based IPQC, rated for $500 \mathrm{~W}, 400 \mathrm{~V} / 1.25 \mathrm{~A}$ is developed under SIM Power System toolbox environment of MATLAB. The performance of the IPQC feeding different types of load such as resistive, inductive and battery load [model as resistive load with its values are taken depending on mode of operation, i.e., CC or constant voltage $(\mathrm{CV})]$ are simulated for CCM. The performance of this mode of operation of converter is evaluated on the basis of various performance parameters including waveforms of supply voltage $\left(\mathrm{v}_{\mathrm{s}}\right)$, supply current $\left(\mathrm{i}_{\mathrm{s}}\right)$ and their THDs for estimating the power quality of the system. Simulation study is carried out and the waveforms of circuit parameters like inductor currents $\left(\mathrm{i}_{\mathrm{Li}}, \mathrm{i}_{\mathrm{Lo}}\right)$, switch voltage $\left(\mathrm{V}_{\mathrm{sw}}\right)$, switch current $\left(\mathrm{I}_{\mathrm{sw}}\right)$ and capacitors voltages $\left(\mathrm{v}_{\mathrm{C} 1}, \mathrm{v}_{\mathrm{C} 3}\right)$ are observed. Power quality parameters of the converters are recorded.

Figure 5 Steady state voltage and current waveform of converter fed from $230 \mathrm{~V}$ input voltage source and $500 \mathrm{~W}$ resistive load, (a) source voltage $\left(v_{s}\right)$, source current $\left(i_{s}\right)$ output voltage $\left(V_{d c}\right)$, inductor currents $\left(i_{L i}, i_{L o}\right)(b)$ capacitors voltages $\left(v_{C 1}, v_{C 3}\right)$, switch voltage and current $\left(\mathrm{V}_{\mathrm{sw}}, \mathrm{I}_{\mathrm{sw}}\right)$
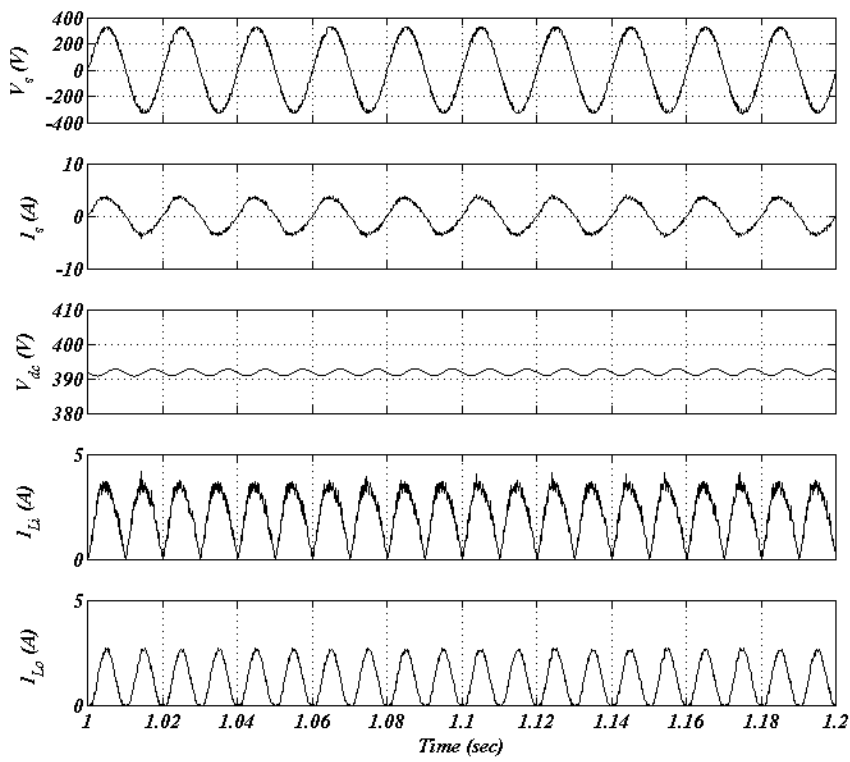

(a)
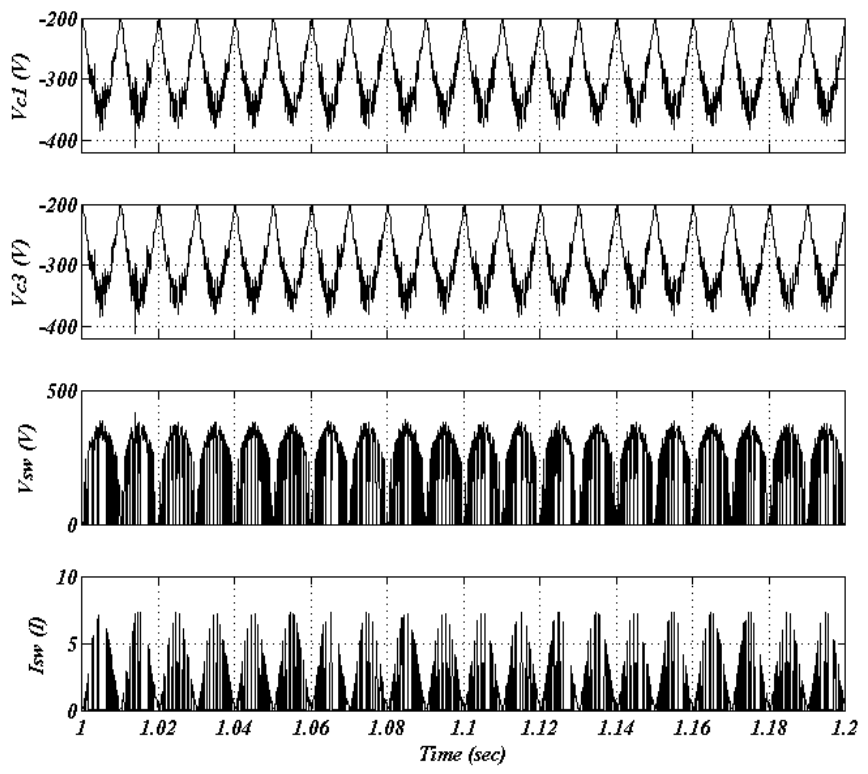

(b) 


\subsection{Steady state performance of hybrid switched} capacitor Cuk converter feeding resistive load

Figure 5 shows the steady state performance of the converter with $230 \mathrm{~V}$ input source voltage and $500 \mathrm{~W}$ resistive load. The waveform of source voltage $\left(\mathrm{v}_{\mathrm{s}}\right)$ and source current $\left(\mathrm{i}_{\mathrm{s}}\right)$ in Figure 5(a) shows that the phase angle between source voltage and input current is almost zero demonstrating improved power quality (unity power factor operation). The regulation of output voltage $\left(\mathrm{V}_{\mathrm{dc}}\right)$ is within limits, showing the effectiveness of closed loop control. The peak voltage and current stresses of the switching device, input inductor current and output inductor current waveforms along with voltage waveform across the intermediate capacitor are observed in Figures 5(a)-5(b) which help in determining the rating of the components. It is observed that both inductor currents and capacitor voltage waveform are continuous. A switch stress of $375 \mathrm{~V}$ and $8 \mathrm{~A}$ are observed. The THD of the input current at full load is observed as $8.9 \%$.

Figure 6 Dynamic performance of converter with source voltage variations, (a) decrease in source voltage $230 \mathrm{~V}$ to $180 \mathrm{~V}$ at time instant $\mathrm{t}=1 \mathrm{sec}(\mathrm{b})$ increase source voltage $180 \mathrm{~V}$ to $230 \mathrm{~V}$ at time instant $\mathrm{t}=1 \mathrm{sec}$

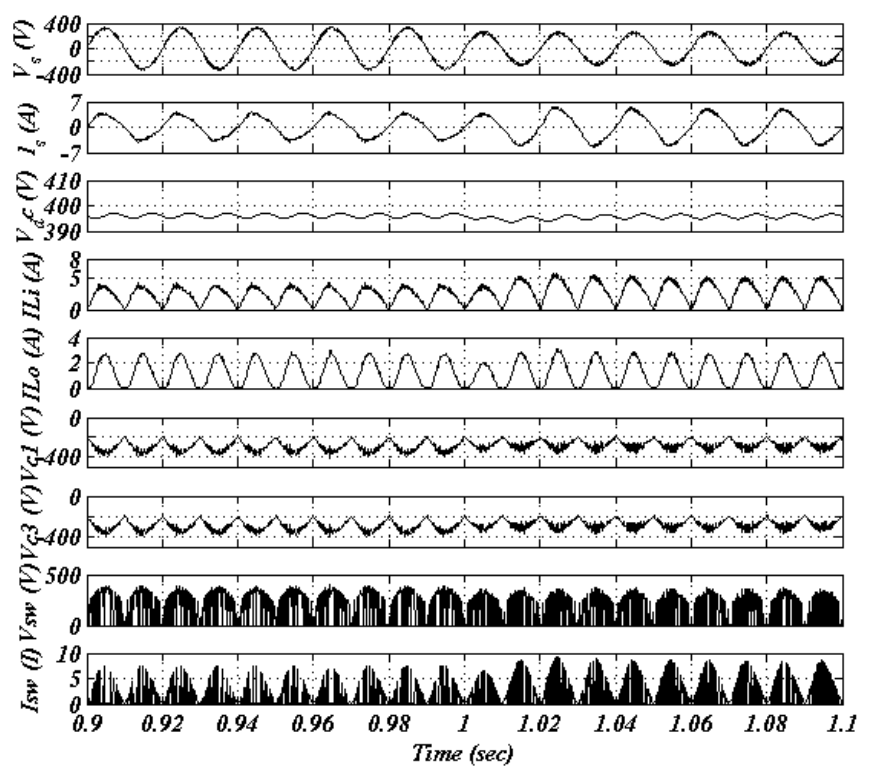

(a)

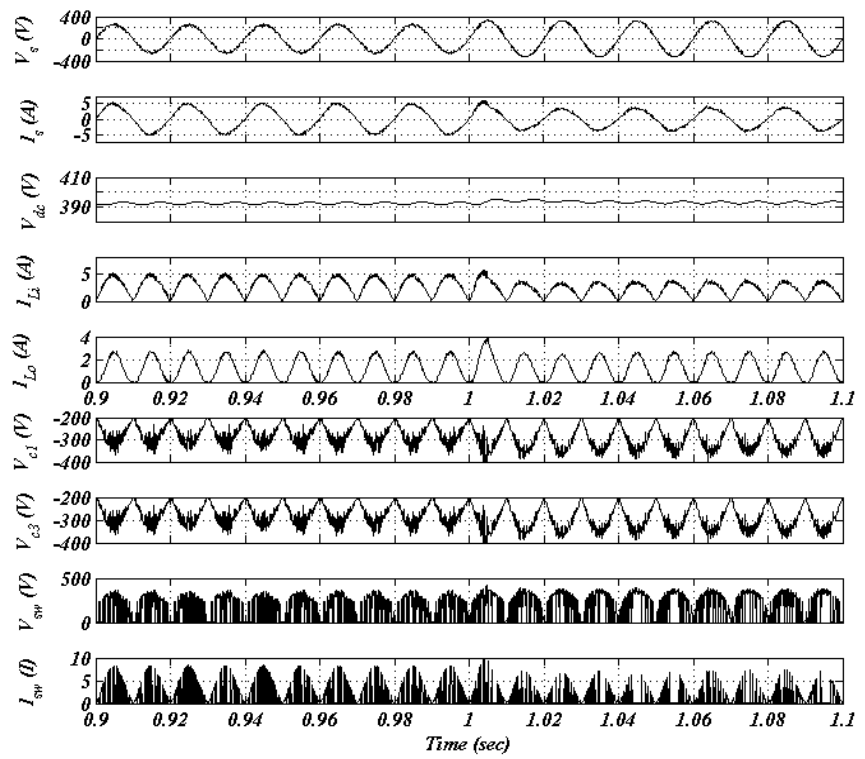

(b) 


\subsection{Transient performance of hybrid switched capacitor Cuk converter feeding the resistive load under source voltage variations}

To study the converter performance against source voltage variation, certain disturbances in source voltage from its nominal voltage $(230 \mathrm{~V})$ are applied, and the response against these variations are observed in Figure 6. A $20 \%$ step decrease in source voltage from its nominal value
$(230 \mathrm{~V})$ is applied at time instant $(\mathrm{t})$ equal to $1 \mathrm{sec}$ as shown in Figure 6(a), and corresponding change is observed in output voltage. It is found that the converter is able to meet the regulation of the output voltage under this disturbance. Furthermore, $20 \%$ step increase in source voltage from $\mathrm{V}_{\mathrm{s}}=180 \mathrm{~V}$, is incorporated and its dynamic performance is evaluated as shown in Figure 6(b). It is observed that the overshoot, under shoot and transient response time are within limits.

Figure 7 Dynamic performance of converter during the interval from $1.3 \mathrm{sec}$ to $1.7 \mathrm{sec}$ with (a) resistive load disturbance and (b) inductive load disturbance

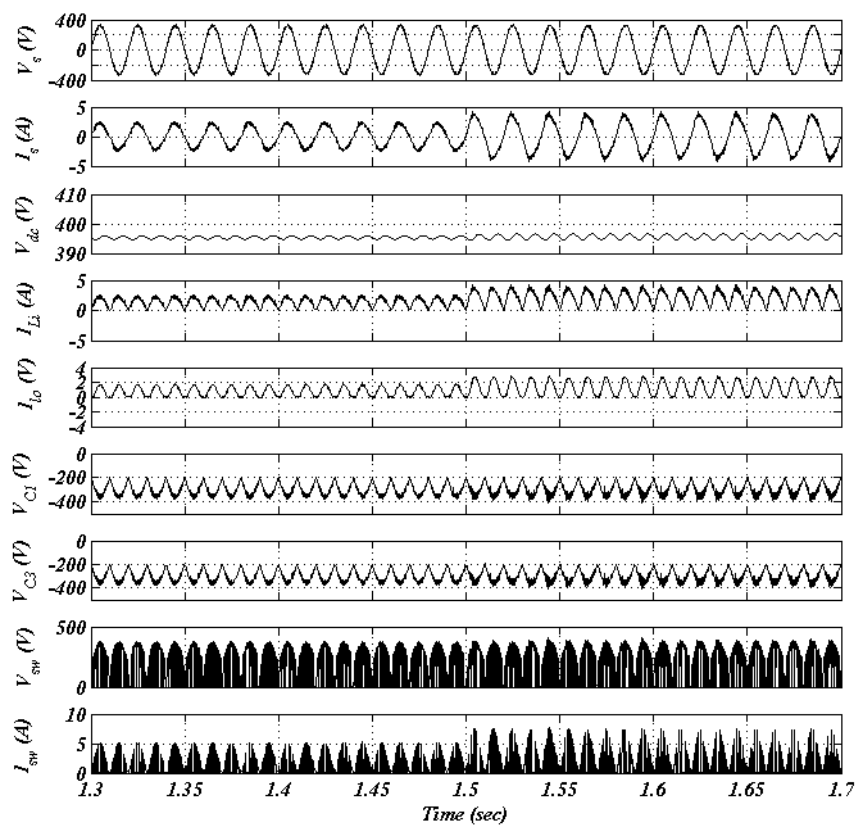

(a)

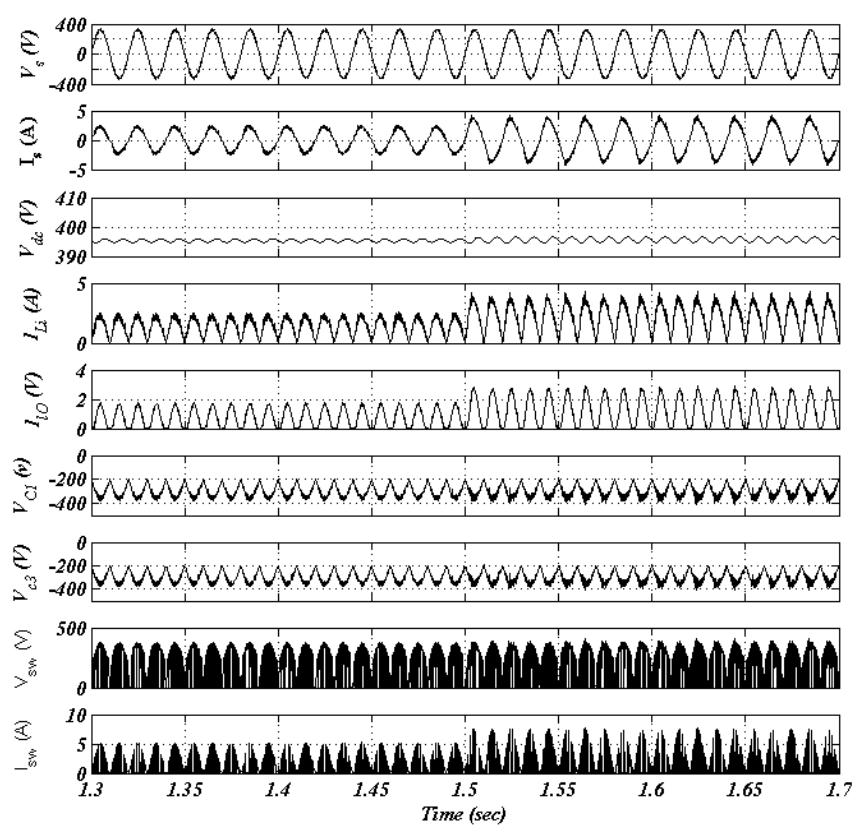

(b) 
Figure 8 Harmonic spectra of input voltage of 230v with (a) 500w resistive load and (b) 500w inductive load
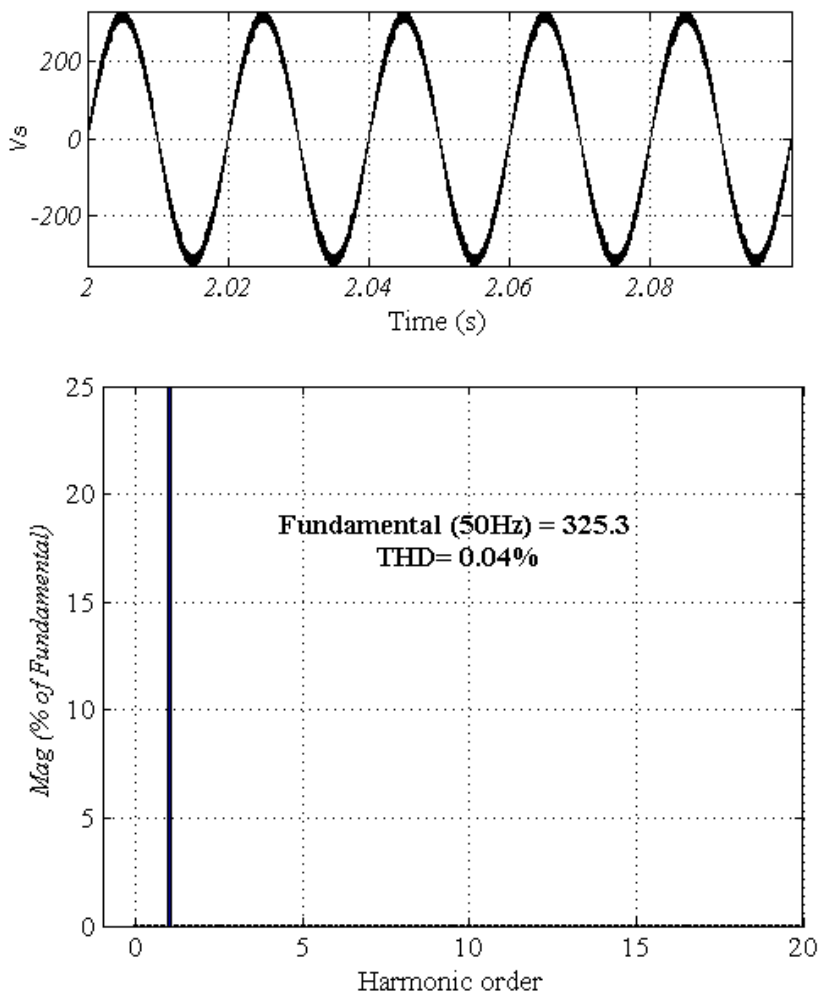

(a)
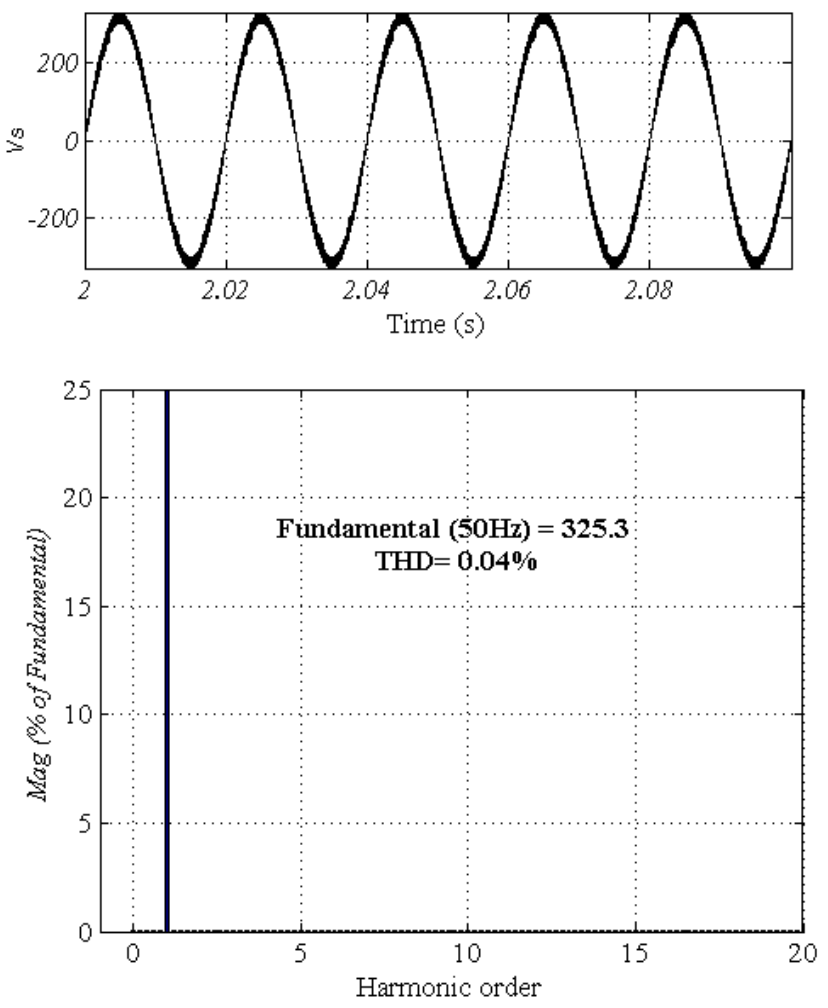

(b)
Figure 9 Harmonic spectra of input current with input voltage of 230 vunder, (a) $500 \mathrm{w}$ resistive load (b) $500 \mathrm{~W}$ inductive load
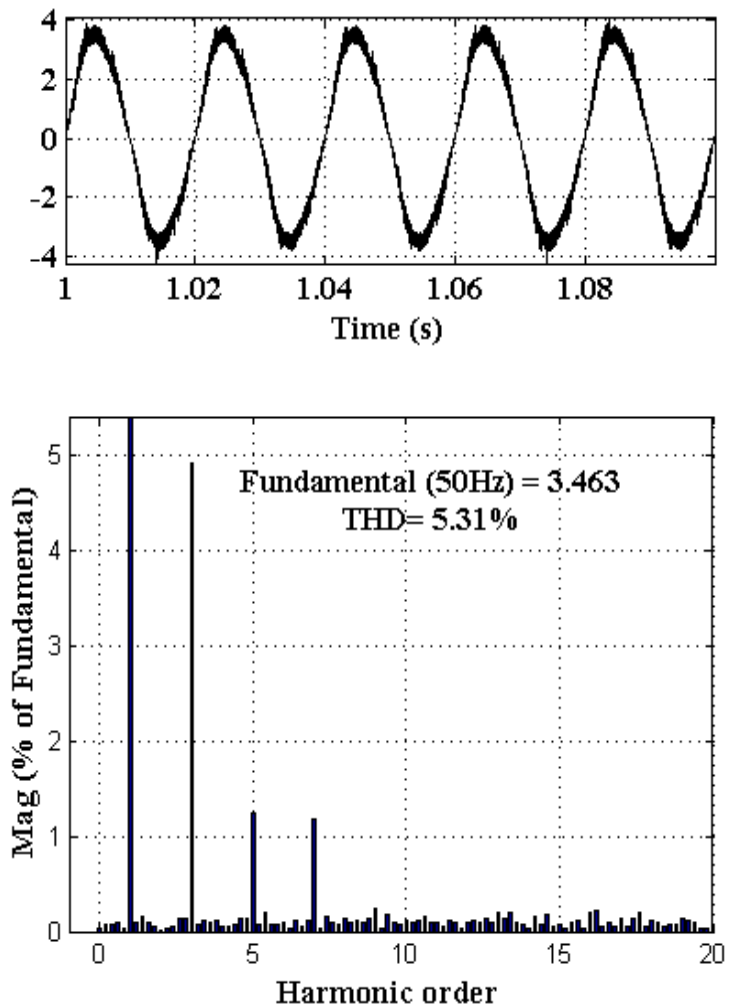

(a)
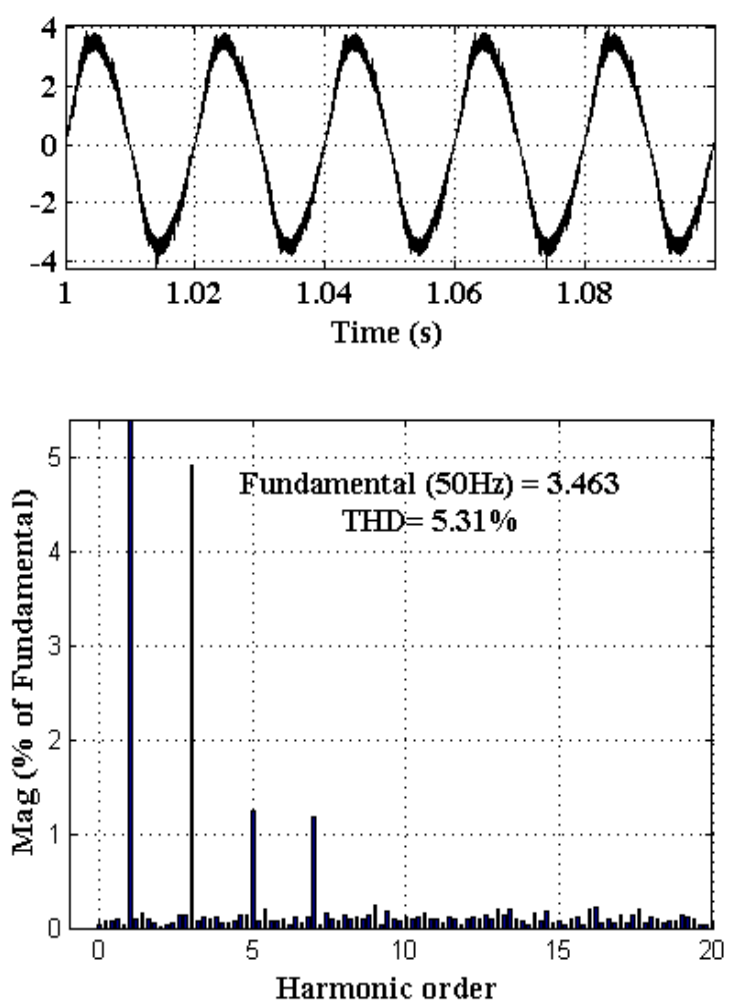

(b) 


\subsection{Transient performance of hybrid switched capacitor Cuk converter feeding varying resistive and inductive loads}

Figure 7(a) shows transient response of converter with varying resistive load at a source voltage of $230 \mathrm{~V} 50 \mathrm{~Hz}$. It is observed that DC output voltage of $400 \mathrm{~V}$ is obtained and at the same time source voltage $\left(\mathrm{v}_{\mathrm{s}}\right)$ and current $\left(\mathrm{i}_{\mathrm{s}}\right)$ are in phase. To assess the dynamic performance, at time instant $\mathrm{t}=1.5 \mathrm{sec}$, a step increase in load from $0.75 \mathrm{~A}$ to $1.25 \mathrm{~A}$ is done and a further decrease in load from $1.25 \mathrm{~A}$ to $0.75 \mathrm{~A}$ is applied at time instant $\mathrm{t}=1.7 \mathrm{sec}$ keeping source voltage $\left(\mathrm{V}_{\mathrm{s}}=230 \mathrm{~V}\right)$ constant. It is observed that in both the cases DC output regulation is obtained. It is observed that both overshoot, under shoot and transient response time are within limit.

Figure 7(b) shows the transient response of converter with varying inductive load at a source voltage of $230 \mathrm{~V}$ $50 \mathrm{~Hz}$. At time instant $\mathrm{t}=1.5 \mathrm{sec}$, a step increase in load from $0.75 \mathrm{~A}$ to $1.25 \mathrm{~A}$ is applied and further decrease in load from $1.25 \mathrm{~A}$ to $0.75 \mathrm{~A}$ is applied at time instant $\mathrm{t}=1.7 \mathrm{sec}$ keeping source voltage $\left(\mathrm{V}_{\mathrm{s}}=230 \mathrm{~V}\right)$ constant. It is observed that in both the cases DC output regulation is obtained. It is observed that both overshoot, under shoot and transient response time are within limits.

\subsection{Harmonic spectra of input voltage and input current of hybrid switched capacitor Cuk converter feeding resistive and inductive load at 230 V input.}

During battery charging mode of converter, the input voltages along with its harmonic spectra and THD has been recorded as shown in Figure 8. The waveforms are captured during $\mathrm{CV}$ mode of operation.

Table 1 Power quality indices under different loads in $\mathrm{cv}$ mode of battery charging

\begin{tabular}{|c|c|c|c|c|c|c|}
\hline \multirow{2}{*}{$\begin{array}{l}\text { Supply } \\
\text { voltage } \\
\left(V_{\mathrm{s}}\right)\end{array}$} & \multicolumn{3}{|c|}{$\begin{array}{c}\text { Resistive load of } \\
500 \mathrm{~W} \text { (system working } \\
\text { in CV mode) }\end{array}$} & \multicolumn{3}{|c|}{$\begin{array}{c}\text { Inductive load of } \\
500 \mathrm{~W} \text { (system working } \\
\text { in CV mode) }\end{array}$} \\
\hline & $V_{\text {sTHD }}$ & $I_{\mathrm{sTHD}}$ & $P F$ & $V_{\text {sTHD }}$ & $I_{\mathrm{sTHD}}$ & $P F$ \\
\hline 90 & $0.49 \%$ & $7.24 \%$ & 0.9973 & $0.49 \%$ & $7.24 \%$ & 0.9973 \\
\hline 120 & $0.18 \%$ & $7.02 \%$ & 0.9975 & $0.18 \%$ & $7.08 \%$ & 0.9975 \\
\hline 150 & $0.11 \%$ & $7.63 \%$ & 0.9971 & $0.11 \%$ & $7.63 \%$ & 0.9971 \\
\hline 200 & $0.07 \%$ & $8.01 \%$ & 0.9968 & $0.07 \%$ & $8.01 \%$ & 0.9968 \\
\hline 230 & $0.06 \%$ & $8.94 \%$ & 0.9960 & $0.05 \%$ & $8.51 \%$ & 0.9963 \\
\hline 265 & $0.04 \%$ & $8.33 \%$ & 0.9965 & $0.04 \%$ & $8.33 \%$ & 0.9965 \\
\hline
\end{tabular}

Figure 8(a) and Figure 8(b) show the THD of input voltage when converter feeds power to $500 \mathrm{~W}$ resistive load and inductive load respectively. Figure 9(a) and Figure 9(b) show input current waveform with harmonic spectra under aforesaid loads. THD of the input current at $500 \mathrm{~W}$ resistive load and inductive load respectively is captured. Table 1 shows power quality indices under different loads indicating voltage THD, current THD and total power factor for resistive and inductive load in CV mode of battery charging. Table 2 shows tabular column listing voltage THD, current THD and total power factor for resistive load in CC mode.

Table 2 Power quality indices in cc mode of battery charging

\begin{tabular}{lccc}
\hline \multirow{2}{*}{$\begin{array}{l}\text { Supply } \\
\text { voltage }\left(V_{\mathrm{s}}\right)\end{array}$} & \multicolumn{2}{c}{$\begin{array}{c}\text { Resistive load drawing current of } 1.25 \mathrm{~A} \\
(\text { system working in CC mode) }\end{array}$} \\
\cline { 2 - 4 } & $V_{\text {sTHD }}$ & $I_{\text {sTHD }}$ & $P F$ \\
\hline 90 & $0.06 \%$ & $4.10 \%$ & 0.99 \\
120 & $0.06 \%$ & $2.63 \%$ & 0.99 \\
150 & $0.06 \%$ & $2.67 \%$ & 0.99 \\
200 & $0.06 \%$ & $2.21 \%$ & 0.99 \\
230 & $0.06 \%$ & $5.09 \%$ & 0.99 \\
265 & $0.06 \%$ & $12.77 \%$ & 0.99 \\
\hline
\end{tabular}

\section{Conclusions}

The hybrid switched capacitor Cuk converter based improved power quality AC-DC converter is proposed for battery charging application. The design and simulation study are carried out. The simulation results are obtained under dynamic load conditions, and results demonstrate that the proposed converter is able to provide regulated output voltage irrespective of supply and load variations. The power quality indices like THD, PF are evaluated to demonstrate the performance of the converter. The converter is evaluated both in steady state and transient conditions. The power quality indices are evaluated both in $\mathrm{CC}$ and $\mathrm{CV}$ modes of battery charging. Based on study, it concludes that hybrid switched capacitor Cuk converter based power factor correction converter offers high stepup gain and low-voltage stress across the switch. Additionally, meets the power quality indices at its ac input source as prescribed by IEEE Standard 519:1992/IEC 61000-3-2, 2000 standards. From the voltage ratio of the converter, it is observed that the duty cycle of the proposed converter is les than the boost converter for the boost version of switched capacitor Cuk converter. This resulted in less average current through the switch, contributing for reduced conduction loss. The voltage stress across the switch calculated according to proposed circuit configuration is found to be less than the boost converter, thus contributing for reduced switching loss. Thus the efficiency of the proposed converter showed significant improvement with respect to boost converter.

\section{References}

Axelrod, B., Berkovich, Y. and Ioinovici, A. (2003) 'Transformer less DC-DC converters with a very high DC line-to-load voltage ratio', in Proc. of the International Symposium on Circuits and Systems, pp.435-438.

Axelrod, B., Berkovich, Y. and Ioinovici, A. (2005) 'Hybrid switched-capacitor-Cuk/Zeta/Sepic converters in step-up mode', in Proc. IEEE International Symposium on Circuits and Systems, pp.1310-1313. 
Axelrod, B., Berkovich, Y., Tapuchi, S. and Ioinovici, A. (2009) 'Single-stage single-switch switched-capacitor buck/buckboost-type converter', IEEE Transactions on Aerospace and Electronic Systems, April, Vol.45, No.2, pp.419-430.

Baggini, A. (2008) Hand book of Power Quality, John Wiley and Sons Inc., USA.

IEEE Standard 519 (1992) IEEE Recommended Practices and Requirements for Harmonics Control in Electric Power System.

Inoue, S., Shimizu, T. and Wada, K. (2003) 'Control methods and compensation characteristics of a series active filter for the neutral conductor', in Proc. 29th Annual Conference of the IEEE Industrial Electronics Society, pp.2282-2287.

International Standard (2000) Limits for Harmonic Current Emissions (Equipment input current $\leq 16$ A per phase), IEC 61000-3-2.

Ismail, E.H., Sabzali, A.J. and Al-Saffar, M.A. (2008) 'Buck-boost-type unity power factor rectifier with extended voltage conversion ratio', IEEE Transactions on Industrial Electronics, March, Vol. 55, No. 3, pp.1123-1132.

Kwon, J-M. and Kwon, B-H. (2009) 'Highstep-up active-clamp converter with input-current doubler and output-voltage doubler for fuel cell power systems', IEEE Transactions on Power Electronics, January, Vol. 24, No.1, pp.108-115.

Liu, R., Dow, L. and Liu, E. (2011) 'A survey of PEV impacts on electric utilities', in Proc. IEEE PES Innovative Smart Grid Technologies, pp.1-8.

Mikkili, S. and Panda, A. (2016) Power Quality Issues, Current Harmonics, CRC Press, Boca Raton, USA.
Mohan, N., Undeland, T.M. and Robbin, W.P. (2007) Power Electronics: Converters, Applications, and Design, Wiley, India.

Putrus, G.A., Suwanapingkarl, P., Johnston, D., Bentley, E.C. and Narayana, M. (2009) 'Impact of electric vehicles on power distribution networks', in Proc. IEEE Vehicle Power and Propulsion Conference, pp.827-831.

Rashid, M.H. (2011) Power Electronics handbook Devices, Circuits and Applications, Elsevier Inc., USA.

Rutherford, M.J. and Yousefzadeh, V. (2011) 'The impact of electric vehicle battery charging on distribution transformers', in Proc. Twenty-Sixth Annual IEEE Applied Power Electronics Conference and Exposition, pp.396-400.

Singh, B., Singh, B.N., Chandra, A., Al-Haddad, K., Pandey, A. and Kothari, D.P. (2003) 'A review of single-phase improved power quality AC-DC converters', IEEE Transactions on Industrial Electronics, October, Vol. 50, No. 5, pp.962-981.

Singh, B., Singh, S., Chandra, A. and Al-Haddad, K. (2011) 'Comprehensive study of single-phase ac-dc power factor corrected converters with high-frequency isolation', IEEE Transactions on Industrial Informatics, November, Vol.7, No.4, pp.540-556.

Wai, R-J. and Duan, V (2005) 'High step-up converter with coupled-inductor', IEEE Transactions on Power Electronics, September, Vol. 20, No. 5, pp.1025-1035.

Zadeh, J.K. and Farjah, E. (2009) 'New control technique for compensation of neutral current harmonics in three-phase four-wire systems', in Proc. IEEE Bucharest PowerTech, pp.1-6. 